\title{
Effective workplace strategies to support employee wellbeing during a pandemic
}

\author{
SANNA K. MALINEN*, JENNIFER HOI KI WONG** and KATHARINA \\ NÄSWALL ${ }^{* * *}$
}

\begin{abstract}
While the long-term impacts of the Covid-19 pandemic are yet to be realised, there is no doubt that the wellbeing of many are and will be affected. Workplaces have a major influence on people's quality of life, and have the ability to impact employee wellbeing. Understanding how organisations can support employees' wellbeing in a disaster context is essential for organisational and community recovery. In this paper, we make recommendations for organisational leaders based on past research on employee wellbeing in post-disaster context and on preliminary evidence from an ongoing study in the Covid-19 context. In the present study, we investigated what job resources employees found supportive during Aotearoa | New Zealand's response to the Covid-19 pandemic and how these resources related to their hedonic and eudaimonic wellbeing at that time. Employees $(n=75)$ took part in an online survey, which included both open-ended and quantitative measures on job resources and wellbeing. Qualitative findings suggest that providing a sense of job security, effective communications, flexibility and job control, recognition of extra efforts to accommodate changes, individualised support to continue working, and expressing concern for employees' health and wellbeing were salient job resources. The quantitative results largely supported these findings, although the strength of the relationships varied between the type of resources and the different conceptualisations of wellbeing. We conclude this paper by providing recommendations for how organisations can support their employees during this period of change and uncertainty.
\end{abstract}

Keywords: Covid-19, employee wellbeing, job resources and demands, eudaimonic, hedonic, wellbeing, organisational support

\section{Introduction}

The global Covid-19 pandemic impacts and challenges are yet to be fully realised, but there is no question that there is, and will be, negative effects to people's wellbeing. Individuals' work plays an important part in people's satisfaction with life and can either support or hinder people's sense of good life (Dockery, 2003; Heller et al., 2002; Unanue et al., 2017). In a disaster context, the role of the workplace may be further amplified as workplaces can provide a stabilising force in people's lives when life outside of work is in turmoil (Hobfoll et al., 2007; Malinen et al., forthcoming; Mooney, 2011). This was the experience of many following the Canterbury, Aotearoa / New Zealand (NZ), 2010-2011 earthquakes: Workplaces that supported their employees effectively had higher adaptive capacity, which facilitated organisational recovery (Nilakant et al., 2016; Walker et al., 2020), and had employees who were more willing to go the extra mile in their work-related efforts (Malinen et al., 2019; Näswall et al., 2017). While research from other disasters have also shown the benefits of

\footnotetext{
* Associate Prof., UC Business School, University of Canterbury, New Zealand

** Research Fellow, School of Psychology, Speech and Hearing, University of Canterbury, New Zealand

**** Prof. School of Psychology, Speech and Hearing, University of Canterbury, New Zealand
} 
offering support for employees (e.g., Sanchez et al., 1995), research on what job resources support employee wellbeing during an ongoing disaster deserves further scholarly attention. In particular, little is known about what job resources are most useful for employees coping in the unfolding Covid-19 pandemic. In this paper, we adopt a broad definition of a disaster as "the widespread disruption and damage to a community that exceeds its ability to cope and overwhelms its resources" (Mayner $\&$ Arbon, 2015, p. 24). We argue that the pandemic is a worldwide disaster, characterised by widespread disruption and distress. In areas where the pandemic was contained early on, the level of physical impact has been smaller so far, but the high level of uncertainty and disruption of lives due to various restrictions, including a nationwide lockdown period in NZ, and increasing unemployment, can be characterised as a disaster context. However, we acknowledge that there are various, and more specific, definitions of disasters (see e.g., Mileti, 1999; Perry, 2007) and that there are vast differences in how the current pandemic is impacting individuals, communities and organisations around the world.

This paper aims to present evidence describing what workplaces are doing to help employees' sense of wellbeing during these unprecedented times. We present past literature on post-disaster research that focused on employee wellbeing and preliminary findings from our ongoing Covid-19 research programme to discuss how workplaces can support hedonic and eudaimonic wellbeing during this global pandemic and other disasters. Hedonic and eudaimonic wellbeing, sometimes also known as subjective (i.e., positive emotions) and psychological wellbeing (i.e., human flourishing) respectively, are both important for a comprehensive understanding of optimal human functioning (Diener et al., 1998; Ryan \& Deci, 2001) during a pandemic.

We draw from the occupational psychology model of Job Demands and Resources (Bakker \& Demerouti, 2007; Demerouti et al., 2001) as a framework for this paper. The theory suggests that job demands, such as uncertainty and frequent changes, likely lead to strain if not met by appropriate job resources. In the context of the Covid-19 pandemic, restrictions placed on citizens in NZ and changes at work (e.g. working from home and other adjustments) may be perceived as a significant disruption, and the ongoing uncertainty about how life and work may be impacted can be a strain for employees. At the time of writing, the global situation is only worsening with restrictions still in place or being reintroduced in various locations. Not only can job resources allow employees to better handle the demands at work, the availability of job resources can also motivate employees to engage in goal attainment behaviours that contribute to the overall health of the workplace (e.g., work engagement; Demerouti et al., 2017). Therefore, job resources can have both a protective and a motivational influence on employees. We propose that understanding what job resources are particularly helpful in supporting employee wellbeing during the Covid-19 response can help NZ workplaces, and more importantly the people in them, better navigate through the current and ongoing uncertain times.

Previous research from non-disaster contexts have identified a range of protective and motivational job resources that support employees (Demerouti et al., 2017; Schaufeli \& Taris, 2014). Importantly, the majority of these resources are within the control of organisational leaders to provide, often at relatively low resource cost. For example, having a supportive line manager is critical for employees' job satisfaction, their wellbeing, their commitment to the organisation, and their decision to stay in the job (Arnold, 2017; Gatling et al., 2016). Examples of job resources that protect employees from demands include the provision of clarity about one's job role (Nielsen et al., 2008), leader visibility, and clear communication (Burton et al., 2009). Motivational job resources include the provision of autonomy, opportunities for growth, and social support at work (Breevaart et al., 2015), and recognising and valuing employee efforts and role in achieving the broader organisational mission (Gilbert \& Kelloway, 2018; Mathafena \& Hewitt, 2018). 
While past literature offers some insights into valuable job resources to support employee wellbeing in general, the literature is largely lacking insights into successful job resources for supporting employee wellbeing during an ongoing disruption and/or heightened level of global uncertainty, such as the Covid-19 pandemic. A better understanding of supportive factors and how to provide these for employees will contribute to organisational recovery as employees with better wellbeing are more resilient (Arnetz et al., 2009; Cooper et et al., 2013; Grant et al., 2009; Sarkar \& Fletcher, 2017), productive (Warr \& Nielsen, 2018) and better able to cope with challenges (Bakker \& Costa, 2014; Näswall et al., 2017). Having a better understanding of such supportive factors also enables organisations to better plan and prepare for future crises (e.g., Hatton et al., 2016). Therefore, we are interested in understanding:

Research Question 1 (RQ1). What job resources did NZ employees consider to be important in their organisations' response to the Covid-19 pandemic?

Research Question 2 (RQ2). How do the job resources identified in RQ1 relate to employee hedonic and eudaimonic wellbeing?

We explore what these job resources may be using data from an initial survey of an ongoing research programme that aims to investigate the impact of Covid-19 on employee wellbeing over time. The survey contained job resource-measures that were chosen inductively by the authors (i.e., based on previous research in other disaster contexts), but also included open-ended questions about what job resources were helpful in the Covid-19 context to further refine the measurement for the upcoming phases of the research. For the purpose of this paper, we present our initial findings that follow an embedded mixed methods design (Creswell \& Clark, 2017). Specifically, we use the qualitative responses to answer RQ1, and based on the themes identified for RQ1, selected constructs to examine for RQ2 using the quantitative responses. We present the methods and findings for RQ1 before moving on to the methods and results for RQ2.

\section{Methods: Research Question 1}

\section{Participants and Procedures}

We collected the data during NZ's national Covid-19 response period. This period started on $21^{\text {st }}$ March, and included a nationwide lockdown which started on $25^{\text {th }}$ March 2020, and continued until $27^{\text {th }}$ April, although some restrictions remained in place until $9^{\text {th }}$ June 2020 , after which NZ still kept their borders strictly controlled. During the lockdown period, New Zealanders were required to work from home unless they were "essential workers" (e.g., medical, grocery store employees). Organisations could apply for a national subsidy plan for businesses that were temporarily shut down (e.g., restaurants, hotels) or where employees could not work from home (e.g., construction work), to avoid layoffs. However, the reality was that many businesses announced large-scale layoffs during, or in close proximity to, the lockdown due to lack of business. These layoffs were reported in the media (see, for example, Radio New Zealand, 2020), contributing to a sense of uncertainty for many organisations and individuals, while unemployment levels were reported to have increased from 145,000 at the start of the lockdown (mid-March) to 184,400 at the beginning of May (Peters, 2020).

Our data collection began in the third week of May 2020. New Zealanders were out of lockdown at this stage, but were still under certain restrictions, such as physical distancing. Participants were asked to reflect on the time since the lockdown had begun in responding to the questions. For the initial sample used for this paper, we collected 75 online (Qualtrics) survey responses ( 24 men, 51 women) 
using convenience sampling via social media platforms (Facebook, LinkedIn, Twitter). The average age of the sample was 40.5 years ( $S D=13$ years). The majority of the sample identified as New Zealand European (76 per cent). The majority of the participants were tertiary qualified (55 per cent), and from large organisations (50+ employees; 76 per cent), predominately in science and education industries (48 per cent) and were in permanent roles ( 79 per cent). Approximately 43 per cent of the sample were in roles with supervisory responsibilities. The average length of organisational tenure was 3.5 years ( $\mathrm{SD}=5$ years). During the nation's lockdown, 68 per cent reported that they were working remotely. From the work-related sample descriptive statistics we deduce that the majority of our sample is from NZ's knowledge intensive service sector (MBIE, 2014) (e.g., higher education, high level administrative, professional, scientific, technical services).

\section{Measures and analyses}

The survey contained three open-ended questions asking about how respondents' workplaces were handling the response to Covid-19:

- Top 3 things that your organisation is doing that is helpful in the current Covid-19 situation.

- Top 3 things that your organisation could be doing to assist you during the current Covid-19 situation.

- Top 3 things that your organisation is doing, but is not helpful, in the current Covid-19 situation

The survey also included a number of quantitative measures described below under "Method: Research Question 2."

Thematic coding (Braun \& Clarke, 2006) was conducted on the responses across the three open-ended questions to determine the resources that were indicated to be salient during organisations' response to Covid-19. The analyses were initially conducted by the second author, and the themes were reviewed by the first author. Differences were discussed and resolved to ensure the analyses were trustworthy (Harding \& Whitehead, 2013).

Results and Discussion of RQ 1: What job resources did NZ employees consider to be important in their organisations' response to the national lockdown during the COVID-19 pandemic?

Our analyses revealed six key job resources identified by employees in NZ.

Theme 1: Providing a sense of job security.

This theme covers both job security ("All employees are still working the same number of hours as before, my job feels safe") and financial security ("Reassurance of continued pay").

Theme 2: Providing effective communications.

This theme covers different aspects of communications, including clarity and consistency of information ("Good remote-working guidelines to make things really clear"), regularity and timeliness of communications ("Frequent communications via email regarding current developments at work"), honesty and transparency ("Transparent and consistent communication regarding the situation and how it will affect the company"; "If the organisation needs to downsize, be open and clear about the process - don't leave people hanging"), and richness in delivery ("Connection - my team leader has been excellent at connecting with us individually and as a team"). 
Theme 3: Providing flexibility and sense of job control.

This theme covers input in decision-making ("Devolving some responsibility for decisions down"), flexibility over availability ("Employees are asked to work as close to fulltime as possible, but to arrange that time around the lockdown requirements of their life [e.g., childcare]"), flexibility over location of work ("Allowing staff to stay home if they feel uncomfortable at work, are vulnerable or are needed at home"), empathy about working during the pandemic ("Relaxing work productivity expectations"), and trust in productive work during the pandemic ("Be aware of the fact that we are actually working").

\section{Theme 4: Providing recognition.}

This theme covers expressing appreciation for the extra workload to accommodate changes ("Providing support to those continuing to work with reward and appreciation"; "More recognition of the 'non-normal' situation and expectations").

Theme 5: Expressing concern for employees' health and wellbeing.

This theme covers protecting employees against the risk of Covid-19 ("Full availability of PPE [personal protective equipment] and imposition of social distancing, entry restrictions") and showing concern for employees' mental health during lockdown ("Actively encouraging staff in welfare space").

Theme 6: Providing support for continued work.

This theme covers providing individualised tools and equipment for employees who are continuing to work through the pandemic ("Sending out computers when needed"), providing training and personnel support ("Hiring casual staff to help with increased workload"), and subsidising costs of continued work ("Pay for extra costs associated with home-based work").

Before moving to our second research question, we want to make some observations regarding generalisations of the findings based on our small sample of knowledge intensive service sector employees. Firstly, the majority of the respondents retained their position in the workplace. Due to this, the themes regarding job resources may not reflect the needs of other industries that were severely affected by the national lockdown (e.g., border restriction prevented international tourism, halting operations in hospitality). Secondly, the majority of the respondents worked remotely during the pandemic. Due to this, the specific resources indicated under the 'Providing support for continued work' theme were highly relevant to the technologies and training related to remote working. Furthermore, the specific resources indicated under all subthemes of 'Communications' referred to remote work communications. These themes on job resources may not reflect the needs of other industries that did not rely as heavily on, or are less used to, technologies used for remote working.

\section{Methods: Research Question 2}

\section{Measures and analyses}

The survey was developed based on previous research on job demands and resources as well as on disaster recovery, which meant that some of the themes from the open-ended responses in the survey were not represented in the quantitative section, as these themes represent new knowledge of useful 
organisational support factors during a pandemic. Due to this, the theme of 'Support for continued work' was not part of the quantitative analyses.

Along with established measures of positive affect, negative affect (i.e. hedonic wellbeing), and eudaimonic wellbeing, we deductively chose measures from the survey that best reflected the six themes identified in the qualitative analyses. While other quantitative data were also collected in the survey, due to the small sample size limiting the number of predictors in each model we chose to include only the items that corresponded to the themes identified in the qualitative phase of this study. Further, choosing constructs based on the qualitative phase allowed us to investigate how these resources specifically related to wellbeing. Where single item measures were used, they were chosen for their face validity in correspondence to the themes from the qualitative phase (cf. Fisher, Matthews, \& Gibbons, 2016).

All quantitative measures were framed to recall perceptions of work and wellbeing within the past four weeks. With the exception of positive and negative affect, and wellbeing, all items were answered on a 7-point Likert-type scale using 1 = "Strongly disagree" to 7 = "Strongly agree".

\section{Job security}

Job security was assessed using Hellgren et al.'s (1999) quantitative job insecurity measure $(\alpha=.97)$. The measure contains three items regarding concerns about losing one's job. A sample item is " $I$ am worried about being let go". The items were reversed scored before the mean item-level score was computed, therefore, a higher score indicated more job security.

\section{Communications}

Communications was assessed using one item from Robinson's (1996) organisational trust scale: “ $M y$ organisation is not always honest and truthful". The item was reversed scored so that a higher score indicated better quality communications.

\section{Job control}

Job control was assessed using a single-item measure (Cammann, Fichman, Jenkins, \& Klesh, 1979): "I feel I have a lot of control over how I do my job". A higher score indicated more job control.

\section{Recognition}

Recognition was assessed using an item from Eisenberger et al.'s (2002) perceived supervisory support scale: "The organisation values my contribution to its success". A higher score indicated more recognition.

\section{Concern for wellbeing}

Concern for employees' wellbeing was assessed using an item from Eisenberger et al.'s (2002) perceived supervisory support scale: "The organisation really cares about my well-being". A higher score indicated more perceived organisational concern for employees' wellbeing. 


\section{Positive and negative affect}

Positive and negative affect, representing hedonic wellbeing, was assessed using a short-form of the positive and negative affect schedule (Watson, Clark, \& Tellegen, 1988) developed by Thompson (2007). The measure contains five items regarding discrete positive emotions $(\alpha=.81)$ and five items regarding discrete negative emotions $(\alpha=.68)$, and are answered on a 7-point Likert-type scale using $1=$ "Never" to $7=$ "Always". A sample item for positive affect is "Determined", and a sample item for negative affect is "Afraid". A mean item-level score was computed for both types of affect, and a higher score indicated more of that type of affect.

\section{Wellbeing}

Eudaimonic wellbeing was assessed using the Short Warwick-Edinburgh Mental Wellbeing Scale (Tennant et al., 2007; $\alpha=.88$ ). The measure contains seven items regarding functioning aspects of mental wellbeing, and are answered on a 7-point Likert-type scale using $1=$ "Not at all" to $7=$ "All the time". A sample item is "I am feeling optimistic about the future". A mean item-level score was computed, and a higher score indicated more eudaimonic wellbeing.

To answer our second research question, we ran three multiple linear regressions in SPSS by regressing positive affect, negative affect, and wellbeing onto the five types of resources in separate outcome models. We checked for the assumptions of normality and homoscedasticity using plots of the residuals, linearity using histograms of the distribution of residuals, and threats of multicollinearity using the VIF values. No assumptions were violated for the three regression models.

Results and Discussion of Research Question 2: How do the job resources identified in RQ1 relate to employee hedonic and eudaimonic wellbeing?

Table 1 presents study variables means, standard deviations, and correlations. A summary of the three wellbeing outcome regression models is presented in Table 2. The job resource predictors explained a moderate proportion of variance in the negative affect and wellbeing outcome models, and a small proportion of variance in the positive affect outcome model (however, this was not significant at the conventional level, as $p=.078$ ). Higher levels of job control were significantly associated with higher positive affect; higher job security and higher concern for wellbeing were associated with less negative affect; and job security and recognition were associated with higher eudaimonic wellbeing. Our communication measure was the only resource not predictive of any of the wellbeing outcomes.

Table 1: Means, standard deviations, and correlations of study variables $(n=75)$

\begin{tabular}{lllllllllll}
\hline & & Mean & SD & 1 & 2 & 3 & 4 & 5 & 6 & 7 \\
\hline 1 & Job security & 4.97 & 1.89 & & & & & & & \\
2 & Communication & 4.99 & 1.90 & $.30^{* *}$ & & & & & & \\
3 & Job control & 5.45 & 1.51 & .15 & $.48^{* * *}$ & & & & & \\
4 & Recognition & 5.35 & 1.71 & $.30^{*}$ & $.61^{* * *}$ & $.61^{* * *}$ & & & & \\
5 & $\begin{array}{l}\text { Concern for } \\
\text { health }\end{array}$ & 5.29 & 1.57 & $.25^{*}$ & $.51^{* * *}$ & $.47^{* * *}$ & $.66^{* * *}$ & & & \\
6 & Positive affect & 4.48 & 1.00 & .13 & .15 & $.33^{* *}$ & $.26^{*}$ & .11 & & \\
7 & & & - & & & & & & \\
& Negative affect & 2.50 & 0.85 & $.49^{* * *}$ & -.18 & -.18 & $-.23^{*}$ & $-.33^{* *}$ & -.11 & \\
8 & & & & & & & & & - \\
\multicolumn{2}{l}{ Wellbeing } & 4.74 & 1.06 & $.42^{* * *}$ & $.35^{* *}$ & $.29^{*}$ & $.48^{* * *}$ & $.42^{* * *}$ & $.55^{* * *}$ & $.56^{* * *}$ \\
\hline \multicolumn{2}{l}{ Note: ${ }^{*} p<.05,{ }^{* *} p<.01,{ }^{* * *} p<.001$} & & & & & &
\end{tabular}


Table 2: Summary of the effect of the types of job resources on wellbeing outcomes $(n=75)$

\begin{tabular}{|c|c|c|c|c|c|c|}
\hline & \multicolumn{2}{|c|}{ Positive affect } & \multicolumn{2}{|c|}{ Negative affect } & \multicolumn{2}{|l|}{ Wellbeing } \\
\hline & $B(\mathrm{SE})$ & $\beta(p)$ & $B(\mathrm{SE})$ & $\beta(p)$ & $B(\mathrm{SE})$ & $\beta(p)$ \\
\hline Intercept & $3.18(0.53)$ & & $4.12(0.39)$ & & $2.46(0.47)$ & \\
\hline Job security & $0.05(0.07)$ & $.09(.460)$ & $-0.21(0.05)$ & $-.47(<.001)^{* * * *}$ & $0.16(0.06)$ & $.30(.007)^{* *}$ \\
\hline Communication & $-0.03(0.08)$ & $-.06(.671)$ & $0.04(0.06)$ & $.09(.527)$ & $0.01(0.07)$ & $.01(.932)$ \\
\hline Job control & $0.21(0.10)$ & $.30(.041)^{*}$ & $-0.04(0.07)$ & $-.07(.588)$ & $-0.01(0.09)$ & $-.01(.935)$ \\
\hline Recognition & $0.11(0.11)$ & $.17(.339)$ & $0.05(0.08)$ & $.09(.583)$ & $0.17(0.10)$ & $.28(.086)^{\dagger}$ \\
\hline $\begin{array}{l}\text { Concern for } \\
\text { health }\end{array}$ & $-0.09(0.10)$ & $-.13(.387)$ & $-0.15(0.07)$ & $-.28(.045)^{*}$ & $0.11(0.09)$ & $.17(.227)$ \\
\hline $\begin{array}{l}\text { Overall } \mathrm{F} \\
\text { Adjusted } R^{2}\end{array}$ & \multicolumn{2}{|c|}{$\underline{\underline{\mathrm{F}}(5,69)}=2.08, p=.078$} & \multicolumn{2}{|c|}{$\underline{\mathrm{F}}(5,69)=5.84, p<.001$} & \multicolumn{2}{|c|}{$\begin{array}{l}\mathrm{F}(5,69)=6.67, p<.001 \\
.28, p<.001\end{array}$} \\
\hline
\end{tabular}

Importantly, job security was a significant and the strongest predictor for both negative affect and eudaimonic wellbeing compare to the other types of job resources in the model, particularly for negative affect. This is perhaps not surprising as having concern over one's job security likely leads to negative emotions, such as worry and anxiety, whereas the perception of having security in employment contributes to living a psychologically good quality of life (Lee, Huang, \& Ashford, 2018; Shoss, 2017). Furthermore, job insecurity is likely to be a pervasive demand for some during the Covid-19 pandemic with no anticipated end, which may be why providing job security had a positive impact on both negative affect and eudaimonic wellbeing in our sample.

Transparency in communications was a job resource that did not significantly relate to any of the three wellbeing outcomes. This may be due to our inability in our quantitative investigation (RQ2) to fully capture the entire content domain of the communication theme identified in RQ1, which also contained subthemes of clarity, timeliness, and richness. While it was not significantly associated with our measures of wellbeing, respondents still identified communications as a key job resource, which may be related to other employee outcomes beyond our chosen measure of wellbeing. It is also perhaps noteworthy that our sample size was limited, as data collection is still ongoing, potentially compromising the statistical power to detect significant relationships in our data. To increase power in this small sample, we used a more liberal p-value cut-off of .10, to avoid rejecting results which may have been significant in a larger sample (cf. Aguinis \& Vandenberg, 2014).

\section{General Discussion}

This research investigated the job resources that employees find helpful in disasters and times of uncertainty. As part of our commentary, we presented qualitative findings from an ongoing study on the job resources that employees found important during NZ's response to the Covid-19 pandemic. By using quantitative items selected based on the open-ended findings, we further investigated how some of these resources related to employee wellbeing. Our findings from the survey suggested six key themes on what employees found beneficial during NZ's pandemic response: job security, regular and clear communications, having flexibility and control over how one does their job, being recognised for one's efforts, that the organisation expressed concern for employees' health and providing support for continued work. When examined quantitatively, items on job security, recognition, job control, and concern for wellbeing were found to relate to negative affect and/or eudaimonic wellbeing. The strength of the relationship between these job resources and positive affect were relatively weaker than 
the negative affect and eudaimonic wellbeing models. However, these findings must be interpreted with caution due to the limited sample and potentially compromised statistical power. In this discussion, we will embed our findings from this initial study on past research on employee wellbeing in post-disaster settings.

Given that we collected data during the pandemic response where restrictions were still in place, the focus of these job resources may be on protecting employees for organisational survival, rather than motivating employees for development and growth, during this response phase of the crisis (cf. Petrou et al., 2017). Job control, job security, and concern for wellbeing were significantly related to negative affect and may be particularly critical to foster in the immediate response to a pandemic because, under circumstances of heightened uncertainties, individual decisions and behaviours are predominantly guided by affective emotions (Dimoff et al., 2015; Loewenstein et al., 2001; Nesse \& Klaas, 1994). Meanwhile, job security and recognition were significantly related to eudaimonic wellbeing, and may be particularly critical to keep available over time to foster human potential (Ryan \& Deci, 2001), which is key to individual and organisational resilience and recovery (Arnetz et al., 2009; Grant et al., 2009).

\section{Recommendations for organisations:}

We conclude this paper by offering six practical, evidence-based recommendations for support that leaders can provide employees during an ongoing disaster, many of which come at relatively low resource cost. We base these recommendations not only on the findings from this study, but also from the broader literature on disaster and crisis management. Not only is there a relationship between leadership, employee wellbeing, and performance (Gatling et al., 2016; Montano, Reeske-Behrens, Pundt, \& Hüffmeier, 2016), Effort-Recovery theory (Meijman \& Mulder, 1998) would suggest that employees who are being cared for are likely to reciprocate such efforts with higher efforts (Schaufeli \& Taris, 2014). Furthermore, many OECD countries' health and safety legislation also require employers to provide psychologically safe working conditions (e.g. NZ's Health and Safety at Work Act, 2015), and extending our understanding of supportive job resources also aligns with UN's Sustainable Development Goal 8 of promoting decent work for all (United Nations, 2015). Overall, prioritising employee wellbeing benefits the employees, the organisations and ultimately, our society.

We provide the following recommendations, based on the present study and on past research:

1. Organisational leaders should provide timely and transparent communication through different modes of communication (Mainiero \& Gibson, 2003; McClain, 2007). These communications should include clarity and honesty in addressing issues on job and financial security, which likely promote trust in the organisation.

2. Organisational leaders should acknowledge the added workload and strain associated with working through a disaster. By acknowledging the extra efforts, leaders signal to employees that they are valued and that their contributions are part of the recovery efforts, increasing the likelihood that staff will be willing to contribute further (see also Malinen et al., 2019).

3. Where possible, organisations should offer flexibility in where and when employees do their work, although we acknowledge that this recommendation is highly industry and context dependent, and likely more relevant to knowledge workers (as was the majority of our sample). Past research also supports the benefits of flexibility in responding to employee needs in disaster contexts (Nilakant et al., 2016). 
4. Support from the organisation should not be 'one size fits all', but rather be tailored to individual situations, including management of workload and support for their wellbeing (Nilakant et al., 2013).

5. If/when working away from the regular work location, employees should be equipped with appropriate equipment and skills to use technology effectively. Past research on teleworking also highlights the importance of managerial support for working from home (Choi, 2018).

6. Finally, employees ought not to be considered in the context of work only. While the majority of our sample were employed during the lockdown period, their partners, for example, may not have been so fortunate. The importance of recognising employees' life outside of work is also evidenced in other disaster-related research (Hammer \& Alley, 2020; Mainiero \& Gibson, 2003; Malinen et al., 2019; Näswall et al., 2017).

Last, consideration of wellbeing should extend to the leaders themselves, who are likely under extreme pressures to look after their business, workplaces and teams (Barling \& Cloutier, 2017; Hall et al., 2016; Hammer \& Alley, 2020; Malinen et al., 2019; Näswall et al., 2017). Further, it will be important to keep the support going in the long term: recent research on wellbeing reactions in Germany, where the pandemic has been a reality for longer than in NZ, suggests that wellbeing decreases as the pandemic and its associated effects on society are prolonged (Zacher \& Rudolph, 2020). Organisational leaders will need to be aware of the potential changing impact of the pandemic on all employees, including managers, as the pandemic develops.

\section{Concluding remarks}

Workplaces, and leaders in particular, can have a significant impact on employee wellbeing. During disasters, the importance of workplace resources is perhaps even further amplified, placing organisations in a critical role of looking after their people, their wellbeing, and to contribute to overall societal response and recovery. We show that employees found various resources, many with relatively low resource costs, helpful during the Covid-19 pandemic response period, many of which were related to higher employee wellbeing. We strongly urge workplaces to prioritise their employees' concerns and needs, and to plan for long-term strategies to support employee wellbeing.

\section{References}

Aguinis, H., \& Vandenberg, R. J. (2014). An ounce of prevention is worth a pound of cure: improving research quality before data collection. Annual Review of Organizational Psychology and Organizational Behavior, 1(1), 569-595.

Arnetz, B. B., Nevedal, D. C., Lumley, M. A., \& Lublin, A. (2009). Trauma resilience training for police: Psychophysiological and performance effects. Journal of Police and Criminal Psychology, 24(1), 1-9. https://doi: 10.1007/s11896-008-9030-y

Arnold, K. A. (2017). Transformational leadership and employee psychological well-being: A review and directions for future research. Journal of Occupational Health Psychology, 22(3), 381-393. doi: $10.1037 /$ ocp0000062 
Bakker, A. B., \& Costa, P. L. (2014). Chronic job burnout and daily functioning: A theoretical analysis. Burnout Research, 1(3), 112-119. doi:10.1016/j.burn.2014.04.003

Bakker, A. B., \& Demerouti, E. (2007). The Job Demands-Resources model: state of the art. Journal of Managerial Psychology, 22(3), 309-328. doi: 10.1108/02683940710733115

Barling, J., \& Cloutier, A. (2017). Leaders' mental health at work: Empirical, methodological, and policy directions. Journal of occupational health psychology, 22(3), 394.

Braun, V., \& Clarke, V. (2006). Using thematic analysis in psychology. Qualitative Research in Psychology, 3(2), 77-101. doi: http://dx.doi.org/10.1191/1478088706qp063oa

Breevaart, K., Bakker, A. B., Demerouti, E., \& van den Heuvel, M. (2015). Leader-member exchange, work engagement, and job performance. Journal of Managerial Psychology, 30(7), 754-770. doi: 10.1108/JMP-03-2013-0088

Burton, P., Gorter, J., \& Paul, R. (2009). Recovering from workplace traumatic events. Journal of Employee Assistance, 39(2), 10-11.

Cammann, C., Fichman, M., Jenkins, D., \& Klesh, J. (1979). The Michigan Organizational Assessment Questionnaire. University of Michigan. Ann Arbor.

Choi, S. (2018). Managing Flexible Work Arrangements in Government: Testing the Effects of Institutional and Managerial Support. Public Personnel management, 47(1), 26-50. doi: $10.1177 / 0091026017738540$

Cooper, C., Flint-Taylor, J., \& Pearn, M. (2013). Building Resilience for Success: A Resource for Managers and Organizations. Palgrave McMillan.

Creswell, J. W., \& Clark, V. L. P. (2017). Designing and conducting mixed methods research ( $3^{\text {rd }}$ ed.). SAGE.

Demerouti, E., Bakker, A. B., Nachreiner, F., \& Schaufeli, W. B. (2001). The Job Demands-Resources Model of Burnout. Journal of Applied Psychology, 86(3), 499-512. doi: 10.1037/00219010.86.3.499

Demerouti, E., Van den Heuvel, M., Xanthopoulou, D., Dubbelt, L., \& Gordon, H. J. (2017). Job resources as contributors to wellbeing. In C. L. Cooper \& M. P. Leiter (Eds.), The Routledge Companion to Wellbeing at Work ( $1^{\text {st }}$ ed. pp. 269-283). Routledge Taylor \& Francis Group.

Diener, E., Sapyta, J. J., \& Suh, E. (1998). Subjective Well-Being Is Essential to Well-Being. Psychological Inquiry, 9(1), 33-37. doi: 10.1207/s15327965pli0901_3 
Dimoff, J. K., Collins, L., \& Kelloway, E. K. (2015). Scrambling: An ability and a process. In A. S. Antoniou \& C. L. Cooper (Eds.), Coping, personality and the workplace: Responding to psychological crisis and critical events (pp. 375-389). Farnham: Gower.

Dockery, A. M. (2003). Happiness, life satisfaction and the role of work: Evidence from two Australian surveys. $\quad$ https://melbourneinstitute.unimelb.edu.au/assets/documents/hildabibliography/working-discussion-research-papers/20012004/Dockery happiness_life_satisfaction.pdf

Eisenberger, R., Stinglhamber, F., Vandenberghe, C., Sucharski, I. L., \& Rhoades, L. (2002). Perceived Supervisor Support: Contributions to Perceived Organizational Support and Employee Retention. Journal of Applied Psychology, 87(3), 565-573. doi: 10.1037/00219010.87.3.565

Fisher, G. G., Matthews, R. A., \& Gibbons, A. M. (2016). Developing and investigating the use of single-item measures in organizational research. Journal of Occupational Health Psychology, 21(1), 3-23. doi: 10.1037/a0039139

Gatling, A., Kang, H. J. A., \& Kim, J. S. (2016). The effects of authentic leadership and organizational commitment on turnover intention. Leadership \& Organization Development Journal, 37(2), 181-199. doi: 10.1108/LODJ-05-2014-0090

Gilbert, S. L., \& Kelloway, E. K. (2018). Leadership, Recognition and Well-Being: A Moderated Mediational Model. Canadian Journal of Administrative Sciences / Revue Canadienne des Sciences de l'Administration, 35(4), 523-534. doi: 10.1002/cjas.1477

Grant, A. M., Curtayne, L., \& Burton, G. (2009). Executive coaching enhances goal attainment, resilience and workplace well-being: A randomised controlled study. The Journal of Positive Psychology, 4(5), 396-407. doi: 10.1080/17439760902992456

Hall, C. M., Malinen, S., Nilakant, V., Vosslamber, R., Walker, B., \& Wordsworth, R. (2016). Undertaking business, consumer and organisational research in a post-disaster setting. In C. M. Hall, S. Malinen, R. Vosslamber \& R. Wordsworth (Eds.), Business and Post-disaster Management: Business, organisational and consumer resilience and the Christchurch earthquakes (pp. 251-268). Routledge.

Hammer, L., \& Alley, L. (2020, April 17). Lead with empathy during the COVID-19 crisis. The Conversation. https://theconversation.com/lead-with-empathy-during-the-covid-19-crisis$\underline{135175}$

Harding, T., \& Whitehead, D. (2013). Analysing data in qualitative research. In Z. Schneider, D. Whitehead, G. LoBionda-Wood, J. Haber (Eds.), Nursing \& Midwifery Research: Methods and appraisals for evidence-based practice ( $4^{\text {th }}$ ed, pp. 141-160). Elsevier-Mosby. 
Hatton, T., Grimshaw, E., Vargo, J., \& Seville, E. (2016). Lessons from disaster: Creating a business continuity plan that really works. Journal of Business Continuity \& Emergency Planning, 10(1), 84-92.

Heller, D., Judge, T. A., \& Watson, D. (2002). The Confounding Role of Personality and Trait Affectivity in the Relationship between Job and Life Satisfaction. Journal of Organizational Behavior, 23(7), 815-835. doi: 10.1002/job.168

Hellgren, J., Sverke, M., \& Isaksson, K. (1999). A Two-dimensional Approach to Job Insecurity: Consequences for Employee Attitudes and Well-being. European Journal of Work and Organizational Psychology, 8(2), 179-195. doi: 10.1080/135943299398311

Hobfoll, S. E., Watson, P., Bell, C. C., Bryant, R. A., Brymer, M. J., Friedman, M. J., . . Ursano, R. J. (2007). Five Essential Elements of Immediate and Mid-Term Mass Trauma Intervention: Empirical Evidence. Psychiatry, 70(4), 283-315. doi: 10.1521/psyc.2007.70.4.283

Lee, C., Huang, G.-H., \& Ashford, S. J. (2018). Job Insecurity and the Changing Workplace: Recent Developments and the Future Trends in Job Insecurity Research. Annual Review of Organizational Psychology and Organizational Behavior, 5(1), 335-359. doi: 10.1146/annurev-orgpsych-032117-104651

Loewenstein, G. F., Weber, E. U., Hsee, C. K., \& Welch, N. (2001). Risk as feelings. Psychological Bulletin, 127(2), 267-286.

McClain, M. (2007). Employee crisis communication and disaster assistance planning: Providing disaster assistance to employees and their families. Journal of Business Continuity \& Emergency Planning, 1(1), 213-220.

Mainiero, L. A., \& Gibson, D. E. (2003). Managing employee trauma: Dealing with the emotional fallout from 9-11. Academy of Management Perspectives, 17(3), 130-143.

Malinen, S., Hatton, T., Näswall, K., \& Kuntz, J. (2019). Strategies to enhance employee well-being and organisational performance in a postcrisis environment: A case study. Journal of Contingencies and Crisis Management, 27(1), 79-86. doi: 10.1111/1468-5973.12227

Malinen, S., Näswall, K., \& Hatton, T. (Forthcoming). Employee wellbeing in post-disaster settings. In T. Wall, C. Cooper \& P. Brough (Eds.), The SAGE Handbook of Organisational Wellbeing (pp. forthcoming). SAGE.

Mathafena, D. R., \& Hewitt, P. M. (2018). An Exploratory Inquiry: The Influence of Line Management on an Employee's Wellbeing. African Journal of Hospitality, Tourism and Leisure, 7(4).

Mayner, L., \& Arbon, P. (2015). Defining disaster: The need for harmonisation of terminology. Australasian Journal of Disaster and Trauma Studies, 19, 21-25. 
Meijman, T. F., \& Mulder, G. (1998). Psychological aspects of workload. In P. J. D. Drenth, H. Thierry \& C. J. d. Wolff (Eds.), Handbook of work and organizational psychology ( $2^{\text {nd }}$ ed., pp. 5-33). Psychology Press.

Mileti, D. S. (1999). Disasters by design: a reassessment of natural hazards in the United States. Joseph Henry Press.

Montano, D., Reeske-Behrens, A., Pundt, F., \& Hüffmeier, J. (2016). Leadership, followers' mental health and job performance in organizations: A comprehensive meta-analysis from an occupational health perspective. Journal of Organizational Behavior, 38(3), 327-350. doi: 10.1002/job.2124

Mooney, M. F. (2011). Psychosocial recovery from disasters : a framework informed by evidence. New Zealand Journal of Psychology, 40(4), 26-38.

Näswall, K., Malinen, S., \& Kuntz, J. (2017). Resilience development through an organisation-led well-being initiative. In N. Chmiel, F. Fraccaroli \& M. Sverke (Eds.), An Introduction to Work and Organizational Psychology: An International Perspective (3 ed., pp. 506-513). Wiley.

Nesse, R. M., \& Klaas, R. (1994). Risk perception by patients with anxiety disorders. Journal of Nervous and Mental Disease, 182(8), 465-470.

MBIE (Ministry of Business, Innovation and Employment). (2014). The New Zealand Sectors Report 2014: Knowledge Intensive Services. https://www.mbie.govt.nz/assets/bd287dd4f2/Knowledge-intensive-services-report.pdf

Nielsen, K., Randall, R., Yarker, J., \& Brenner, S.-O. (2008). The effects of transformational leadership on followers' perceived work characteristics and psychological well-being: A longitudinal study. Work \& Stress, 22(1), 16-32. doi: 10.1080/02678370801979430

Nilakant, V., Walker, B., Kuntz, J., de Vries, H. P., Malinen, S., Näswall, K., \& van Heugten, K. (2016). Dynamics of organisational response to a disaster: A study of organisations impacted by earthquakes. In C. M. Hall, S. Malinen, V. R. \& R. Wordsworth (Eds.), Business and Postdisaster Management (pp. 35-47). Routledge.

Nilakant, V., Walker, B., Rochford, K., \& Van Heugten, K. (2013). Leading in a post-disaster Setting: Guidance for human resource practitioners. New Zealand Journal of Employment Relations, $38(1), 1-13$.

Perry, R. W. (2007). What Is a Disaster? In H. Rodríguez, E. L. Quarantelli \& R. R. Dynes (Eds.), Handbook of Disaster Research. Handbooks of Sociology and Social Research. Springer.

Peters, T. (2020). Unemployment Soars In New Zealand. Scoop. https://www.scoop.co.nz/stories/HL2005/S00135/unemployment-soars-in-new-zealand.htm 
Petrou, P., Demerouti, E., \& Xanthopoulou, D. (2017). Regular versus cutback-related change: the role of employee job crafting in organizational change contexts of different nature. International Journal of Stress Management, 24(1), 62-85. doi: 10.1037/str0000033

Radio New Zealand. (2020). Fletcher Building to lay off 1000 staff in New Zealand. https://www.rnz.co.nz/news/business/417066/fletcher-building-to-lay-off-1000-staff-in-newzealand

Robinson, S. L. (1996). Trust and breach of the psychological contract. Administrative Science Quarterly, 14(4).

Ryan, R. M., \& Deci, E. L. (2001). On happiness and human potentials: A review of research on hedonic and eudaimonic well-being. Annual Review of Psychology, 52(1), 141-166.

Sanchez, J. I., Korbin, W. P., \& Viscarra, D. M. (1995). Corporate support in the aftermath of a natural disaster: Effects on employee strains. Academy of Management Journal, 38(2), 504-521.

Sarkar, \& Fletcher. (2017). How resilience training can enhance wellbeing and performance. In M. F. Crane (Ed.), Managing for Resilience A Practical Guide for Employee Wellbeing and Organizational Performance (pp. 227-237): Routledge Taylor \& Francis Group.

Schaufeli, W. B., \& Taris, T. W. (2014). A critical review of the job demands-resources model: Implications for improving work and health. In G. F. Bauer \& O. Hämmig (Eds.), Bridging occupational, organizational and public health: A transdisciplinary approach (pp. 43-68). Springer Science + Business Media.

Shoss, M. K. (2017). Job Insecurity: An Integrative Review and Agenda for Future Research. Journal of management, 43(6), 1911-1939. doi: 10.1177/0149206317691574

Tennant, R., Hiller, L., Fishwick, R., Platt, S., Joseph, S., Weich, S., . . Stewart-Brown, S. (2007). The Warwick-Edinburgh Mental Well-being Scale (WEMWBS): development and UK validation. Health and quality of life outcomes, 5(1), 63-63. doi: 10.1186/1477-7525-5-63

Thompson, E. R. (2007). Development and Validation of an Internationally Reliable Short-Form of the Positive and Negative Affect Schedule (PANAS). Journal of Cross-Cultural Psychology, 38(2), 227-242. doi: 10.1177/0022022106297301

Unanue, W., Gómez, M. E., Cortez, D., Oyanedel, J. C., \& Mendiburo-Seguel, A. (2017). Revisiting the Link between Job Satisfaction and Life Satisfaction: The Role of Basic Psychological Needs. Frontiers in psychology, 8, 680. doi: 10.3389/fpsyg.2017.00680

United Nations. (2015). Transforming our World: The 2030 Agenda for Sustainable Development (A/RES/70/1). https://sustainabledevelopment.un.org/content/documents/21252030\%20Agenda\%20for\%20 Sustainable\%20Development\%20web.pdf 
Walker, B., Malinen, S., Nilakant, V., Näswall, K., \& Kuntz, J. (2020). Resilience-in-action Through an Extended Disaster: the Christchurch Earthquakes. In E. H. Powley, B. Caza \& A. Caza (Eds.), Handbook of Organizational Resilience. Edward Elgar Publishing.

Warr, P., \& Nielsen, K. (2018). Wellbeing and work performance. In S. O. E. Diener, \& L. Tay (eds.), Handbook of well-being. DEF Publishers. doi: nobascholar.com

Watson, D., Clark, L. A., \& Tellegen, A. (1988). Development and Validation of Brief Measures of Positive and Negative Affect: The PANAS Scales. Journal of Personality and Social Psychology, 54(6), 1063-1070. doi: 10.1037/0022-3514.54.6.1063

Zacher, H., \& Rudolph, C. W. (2020). Individual differences and changes in subjective wellbeing during the early stages of the COVID-19 pandemic. American Psychologist. Advanced online publication. doi: http://dx.doi.org/10.1037/amp0000702 